\title{
Research Paper: Pre-Hospital Emergency Services With Emphasis on Traffic Accidents: A Case Study in Mashhad, crossuark Iran
}

Hossein Ebrahimipour ${ }^{1}$, Reza Vafaee Nazhad ${ }^{2}$, Ali Vafaee Najar ${ }^{1}$, Mehdi Yousefi ${ }^{1}$, Elahe Houshmand $^{1}$, Seyede Elahe Hosseini ${ }^{3}$, Hajar Haghighi ${ }^{4}$, Payam Mahmoudian $^{5^{*}}$

1. Health Sciences Research Center, Mashhad University of Medical Sciences, Mashhad, Iran.

2. Taleghani Center for Accident and Emergency Operations, Mashhad University of Medical Sciences, Mashhad, Iran.

3. Department of Management of Healthcare Services, School of Management and Medical Information Sciences, Isfahan University of Medical Sciences, Isfahan, Iran.

4. Institute for Future Studies in Health, Kerman University of Medical Sciences, Kerman, Iran.

5. Department of Health Services Management, School of Health Management and Information Sciences, Iran University of Medical Sciences, Tehran, Iran

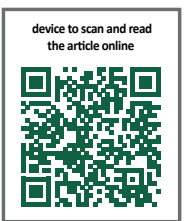

Cftation: Ebrahimipour H, Vafaee Nazhad R, Vafaee Najar A, Yousefi M, Houshmand E, Hosseini SE, et al. Pre-Hospital Emergency Services With Emphasis on Traffic Accidents: A Case Study in Mashhad, Iran. Health in Emergencies and Disasters Quarterly. 2017; 2(3):145-154. https://doi.org/10.18869/nrip.hdq.2.3.145

https://doi.org/10.18869/nrip.hdq.2.3.145

Article info:

Received: 03 Dec. 2016

Accepted: 27 Feb. 2017

Keywords:

Pre-hospital emergency, Traffic accidents, Mashhad City

\section{A B S T RACT}

Background: Pre-hospital emergency service is an important part of any health care system. The present study was conducted to evaluate the pre-hospital Emergency Services 115 of Mashhad City, Iran with emphasis on response to traffic accidents during 2012-2013.

Materials and Methods: In this descriptive cross-sectional and applied study, 53685 files of traffic accident victims related to 42240 missions accomplished during 2012-2013 were evaluated. The study data were collected by referring to the statistics unit of the Center for Medical Emergencies and Accidents. To determine the services performed for the victims, a researcher-designed checklist was used. Descriptive statistics were performed to analyze the raw data. All analyses were done by Excel 2013.

Results: The average (SD) age of traffic accident victims was 29.5(15.69) years. The frequency of accidents was more in September, on Thursdays, and between 6 and 9 PM. About $70 \%$ of missions ended with the transfer the injured to hospitals and average (SD) response times were 8:24 (2:35) minutes in 2012 and 9:01 (2:46) minutes in 2013. The frequency of treatment and dispatch to hospitals by the resident physician were reported as $70.51 \%$ in 2012 and $69.7 \%$ in 2013 . The most frequent action taken were injections $(96 \%)$ and then stabilizing body limbs $(60 \%)$.

Conclusion: Considering the findings of this research, the response time was longer than the standard time. Regarding the performed services, shortcomings in manpower and ambulance equipment can reduce the effectiveness of missions. Therefore, Emergency Center 115 of Mashhad should carry out some interventions to resolve shortages in manpower and equipment to reach standard conditions and provide better services.

\section{* Corresponding Author: \\ Payam Mahmoudian, PhD Candidate}

Address: Department of Health Services Management, School of Health Management and Information Sciences, Iran University of Medical Sciences,

Tehran, Iran.

E-mail:payam_mahmoudian@yahoo.com 


\section{Introduction}

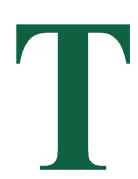

oday, accidents and injuries account for 5 million deaths and more than 100 million disabilities each year [1]. These damages are caused by a wide variety of accidents, including natural and man-made disasters [2].

Accidents, whether natural or man-made, are the main causes of mortality in the world. In the United States, it has been estimated that every citizen would require emergency services at least two times during his lifetime due to accidents [3]. Accidents besides their damages will affect societies and leave injuries and unbearable disabilities [4]. It is anticipated that by 2020, trauma would be the leading or the second cause of mortality in developing and developed countries [5]. These issues have raised the attention of World Health Organization to increasing load of chronic diseases, non-communicable illnesses, trauma and depression, thus calling for rapid and continuous development of emergency treatment. In most countries, this type of treatment is offered by the Emergency Medical Services (EMS) [2].

Pre-hospital cares include services that begin at the patient's side and ends in the hospital emergency ward. Some studies show that these services include up to the time the patient is discharged from hospital. Patients with internal medicine problem (who lack a history of trauma) and patients with trauma at the scene of accidents compose the major types of those needing prehospital care [6]. Emergency care should be understood as a complete system with independent components. These components include pre-hospital care, transportation, and hospital care. Each component is important, however, all should interact properly to have an enduring effect on society's health [7].

EMS act at the intersection of health care, public health, and safety [8] and by definition refers to services that respond to the needs of specific health of people outside of hospitals [2]. In health care systems, the first encounter with critical and emergency patients is generally performed by pre-hospital emergency service [9]. This service is an important part of presenting health care [10] that faces with life threatening conditions outside the hospital. Its main focus is prevention of acute death, and by prompt diagnosis and timely treatment can alter life threatening conditions and limit mortality [11]. Studies show that speedy relief with standard quality can reduce the mortality rate of accidents by $30 \%$, and furthermore, significantly prevents complications resulting from inap- propriate actions and handling of the victims that would have led to their disabilities [12].

The proper function of various parts of this system results in speedy and timely dispatch of ambulance to the patient's side and prevention of death and disability. The success of this system depends on different factors such as the competency of responsible individuals, trained personnel, equipment, coordination, and communication system. The more correct, safer, and faster care for critical patients delivered by EMS, the less would be the mortality and disability resulting from illnesses and diseases. Consequently, that would increase the people's trust on the system [13].

There are two types of responses that are common by pre-hospital emergency systems in various countries; 1) ambulance dispatch with advanced equipment regardless of the type of accident immediately after receiving the first call for help; and 2) receiving information from the person who has contacted them, collecting information, classifying them, and selecting the type and level of service that is going to be dispatched to the scene of accident [7].

In Iran, unintentional accidents with 28000 fatalities per year is the second cause of mortality and Iran is among the countries with the highest rate of fatalities in the world resulting from traffic accidents. The rate of road accidents in Iran is 20 times the world average, and according to the statistics given, in every 19 minutes one person loses his life in Iran due to traffic accidents. Moreover, 50\% percent of fatalities in traffic accidents in Iran occur in the first hour after the accident, $25 \%$ while the injured being transferred to hospital, and $25 \%$ relate to infections arising from complications that develop in hospitals [14]

According to regulations of Iran Comprehensive Coverage of Medical Emergencies, the response time in $80 \%$ of cases is less than 8 minutes in cities and less than 15 minutes for road accidents for pre-hospital emergency care [14]. In order to improve the quality of pre-hospital treatment services in our country, the status quo should be reviewed and evaluated. Certainly, evaluation of prehospital urban health care system is very difficult because its effectiveness and values are hard to measure.

In a study conducted about the efficiency of emergency services in Rasht City, the importance of accurate and exact time measurement has been mentioned for supervising the pre-hospital care operation. In another study about traffic accidents injuries, some solutions have been proposed to reduce these injuries. Considering the importance of this issue, the present study was conducted to evaluate the pre-hospital Emergency Services 115, with 
the emphasis on response to traffic accidents in Mashhad City during 2012-2013.

\section{Materials and Methods}

In this descriptive cross-sectional and applied study, 53685 files of urban traffic accident victims corresponding to 42240 hospital emergency missions during 2012-2013, were examined. The difference in the study populations (victims and missions) is because there has been more than one victim in some emergency missions. The study data were collected from the files of traffic accident victims (by full enumeration) from the city of Mashhad Medical Emergencies and Accidents Center Statistics Unit, in which the frequency of Emergency 115 missions during various times, the mission time intervals, results of missions, instructions given by the resident physician at the message center, and services provided for the victims, were extracted.

The checklist compiled by the researcher was used to determine the services provided to the victims. First, a checklist of provided services was prepared by reviewing 550 cases in 2013. The initial checklist included 26 performed services. Then, the list was revised by the experts from the Emergency 115 of Mashhad and some duplicate services were deleted and some services were added to the list and eventually a final checklist of 20 services was obtained and confirmed by 5 experts using content validity. The checklist reliability was examined through the test-retest method with one week interval $(\alpha=0.83)$. In the end, 520 files were selected through systematic sampling method to determine the services provided to the victims. For data analysis, the descriptive statistics including frequency, percentage, mean, and standard deviation were calculated using Excel 2013.

\section{Results}

As shown in Table 1, men comprised a high percentage of victims during 2012 and 2013. The average age of the victims has been recorded as 29 years, and most victims were in the age group of 15-25 years during the study years. The frequency of accidents was mostly in September, on Thursdays, and between 6 to $9 \mathrm{PM}$. As is seen in Table 2, transfer to hospital, mission cancellation, and transferring to hospital by private vehicle before ambulance arriving the accident scene, respectively, were reported as the most results of Emergency 115 missions.

As is seen in Table 3, the average response time (receiving the first call from the public till the time ambulance arrives at the scene of accident) in the missions performed by Emergency 115 in Mashhad during 2012 and 2013 were respectively 8:24 minutes, and 9:01 minutes. According to Table 4, treatment and dispatch to the hospital by the resident physician was the most frequent instructions reported by the crew of medical emergencies. However, the medical emergencies' crew have not necessarily communicated with the resident physician at the Emergency Call Center in all missions.

As is seen in Table 5, a total of 36 active ambulances and 16 auxiliary ambulances (ambulances that in the operation base are not considered as active ambulances, however, in case of need they are used to deliver service) in Mashhad Emergency 115 Center were involved in delivering services to the patients. According to Table 6, the services provided to the victims have been listed. The most frequent services were injections (intravenous injection and serum therapy) and stabilizing body limbs that have been performed for approximately $96 \%$ and $60 \%$ of victims, respectively.

Table 1. Demographics of victims and frequency of accidents

\begin{tabular}{|c|c|c|c|}
\hline \multicolumn{2}{|c|}{ Variable } & \multirow{2}{*}{$\begin{array}{c}\mathbf{2 0 1 2}(\%) \\
38.62\end{array}$} & \multirow{2}{*}{$\begin{array}{c}\text { 2013(\%) } \\
59.99\end{array}$} \\
\hline & Male & & \\
\hline \multirow[t]{2}{*}{ Gender } & Female & 10.42 & 23.21 \\
\hline & Not recorded in the file & 50.96 & 16.8 \\
\hline \multirow{2}{*}{ Age, year } & Mean and standard deviation & $29.5 \pm 15.69$ & $29.8 \pm 15.9$ \\
\hline & Most frequent age group & $16-25(31.41 \%)$ & $16-25(30.28 \%)$ \\
\hline \multirow{3}{*}{ Peak of accidents } & Month & September (11.73\%) & September (11.86\%) \\
\hline & Days of the week & Thursday (15.33\%) & Thursday (15.48\%) \\
\hline & Day hours & 6-9 PM (19.40\%) & 6-9 PM (20.06\%) \\
\hline
\end{tabular}


Table 2. Results of emergency 115 missions on traffic accidents in Mashhad

\begin{tabular}{|c|c|c|c|c|}
\hline \multirow{2}{*}{ Mission Result } & \multicolumn{2}{|c|}{2012} & \multicolumn{2}{|c|}{2013} \\
\hline & No. & $\%$ & No. & $\%$ \\
\hline Transfer to hospital & 14875 & 70.51 & 14733 & 70.69 \\
\hline Mission cancelled & 4251 & 20.18 & 4695 & 22.24 \\
\hline Transfer to hospital by private vehicle before ambulance arrives at the scene & 1694 & 8.03 & 1454 & 6.88 \\
\hline Transfer to hospital while under CPR (cardiopulmonary resuscitation) & 102 & 0.48 & 141 & 0.67 \\
\hline Death before the ambulance arrives at the scene & 49 & 0.23 & 42 & 0.02 \\
\hline Transfer to another ambulance & 120 & 0.57 & 65 & 0.31 \\
\hline
\end{tabular}

Table 3. Average time intervals of traffic accident missions of emergency 115 in Mashhad

\begin{tabular}{|c|c|c|c|c|}
\hline \multirow{2}{*}{ Time Interval } & \multicolumn{2}{|c|}{2012} & \multicolumn{2}{|c|}{2013} \\
\hline & Mean & SD & Mean & SD \\
\hline $\begin{array}{l}\text { Receiving calls from the public till announcing the mission to } \\
\text { the base }\end{array}$ & 21 seconds & 8 seconds & 19 seconds & 7 seconds \\
\hline $\begin{array}{l}\text { Announcing the mission to the operation base till the ambu- } \\
\text { lance leaving the base }\end{array}$ & $\begin{array}{l}1 \text { minute, } 52 \\
\text { seconds }\end{array}$ & 43 seconds & $\begin{array}{l}1 \text { minute, } 55 \\
\text { seconds }\end{array}$ & 44 seconds \\
\hline Leaving the operation base till reaching the victim's side & $\begin{array}{l}6 \text { minutes, } \\
14 \text { seconds }\end{array}$ & $\begin{array}{l}1 \text { minute, } 45 \\
\text { seconds }\end{array}$ & $\begin{array}{l}6 \text { minutes, } 15 \\
\text { seconds }\end{array}$ & $\begin{array}{l}1 \text { minute, } 55 \\
\text { seconds }\end{array}$ \\
\hline $\begin{array}{l}\text { Receiving the call from the public till reaching the victim's side } \\
\text { (response time) }\end{array}$ & $\begin{array}{l}8 \text { minutes, } \\
24 \text { seconds }\end{array}$ & $\begin{array}{l}2 \text { minutes, } \\
35 \text { seconds }\end{array}$ & $\begin{array}{l}9 \text { minutes, } 1 \\
\text { second }\end{array}$ & $\begin{array}{l}2 \text { minutes } 46 \\
\text { seconds }\end{array}$ \\
\hline Departing the scene of accident till reaching the hospital & $\begin{array}{l}11 \text { minutes, } \\
29 \text { seconds }\end{array}$ & $\begin{array}{l}3 \text { minutes, } \\
39 \text { seconds }\end{array}$ & $\begin{array}{c}12 \text { minutes, } 17 \\
\text { seconds }\end{array}$ & $\begin{array}{l}4 \text { minutes, } \\
25 \text { seconds }\end{array}$ \\
\hline & & & $\begin{array}{l}\text { Hlealth in } \\
\text { Emergencies and }\end{array}$ & asters [Oluarter| \\
\hline
\end{tabular}

Table 4. Instructions of the resident physician at the call center to the medical emergencies crew

\begin{tabular}{|c|c|c|c|c|}
\hline \multirow{2}{*}{ Instructions by Resident Physician at the Call Center } & \multicolumn{2}{|c|}{2012} & \multicolumn{2}{|c|}{2013} \\
\hline & No. & $\%$ & No. & $\%$ \\
\hline Treatment and dispatch to hospital & 17699 & 90.15 & 17454 & 90.4 \\
\hline Monitoring vital signs & 1701 & 8.45 & 1508 & 7.84 \\
\hline Non-emergency case and advised to refer personally to the clinic & 414 & 1.4 & 294 & 1.76 \\
\hline
\end{tabular}

\section{Discussion}

The present study was conducted to evaluate the function and efficiency of pre-hospital emergency services of Mashhad during 2012 and 2013. The accidents victims were $60 \%$ males, $17 \%$ females, and in $23 \%$ of cases the gender was not recorded in the files. Considering that most car and motorcycle drivers are men, these statistics are justifiable. In Hajinabi and colleagues study [15], $32 \%$ of victims were males and $4 \%$ were females and the gender of $64 \%$ of victims was not specified in the files. 
Table 5. Frequency and average performance of emergency 115 ambulances of Mashhad City

\begin{tabular}{ccc}
\hline & Active Ambulances & Auxiliary Ambulances \\
\hline Frequency & 36 & 16 \\
Average performance $(\mathrm{Km})$ & 116204 & 84016 \\
\hline & & $\begin{array}{l}\text { IPlealth in } \\
\text { Emergencies and |D]isasters [Oluarterly }\end{array}$
\end{tabular}

Table 6. Frequency of services provided by emergency medical services crew to the patients

\begin{tabular}{ccc}
\hline Services Provided to the Patients & No. & $\%$ \\
\hline Injections (intravenous injection and serum therapy) & 502 & 96.72 \\
Monitoring vital signs & 276 & 53.18 \\
Medical consultation & 288 & 55.49 \\
Oxygen therapy & 238 & 45.86 \\
Stabilization of limbs & 308 & 59.35 \\
Dressing & 172 & 33.15 \\
Control of bleeding in patients & 10 & 1.93 \\
Suction & 6 & 1.16 \\
Intubation & 4 & 0.7 \\
CPR (cardiopulmonary resuscitation ) & 2 & 0.39 \\
\hline
\end{tabular}

Also, in Fars Najjari study [16], 73\% of victims were males and $27 \%$ were females.

In Monsef Kasamaei study in Gilan Province, $76.9 \%$ of traffic accidents victims were males [17]. Also, in other parts of the world, such as Ferrando study in Spain [18] and the studies conducted in India [19], men comprised the majority of victims in traffic accidents. It seems that educational and cultural interventions should be planned mostly by emphasis on the male population.

In the present study, the average (SD) age of victims was equal to 29 [15] years and most victims (31\%) were in the age range of 15 to 25 years. In Hajinabi and colleagues study in Tehran [15], most traffic accident victims were in the age group of 20 to 29 years with average age of 35.5 years. Also in the study examining the prehospital causes of accident victims taken to Shohadaye Haftom-e Tir Hospital [16], 27\% of victims were in the age group of 20 to 29 years, which had the highest frequency among various age groups. Results of the research showed that the highest risk group in traffic accidents comprised young adults, especially men, and this finding is in line with the findings of other studies in Khuzestan [20], Shahroud [21], and Gilan [17]. This is due to greater use of motorcycles by young adults and their disregard for traffic rules. Education through mass media and educational institutions directed toward young people and adolescents about the importance of observing traffic rules and use of safety helmets when riding motorcycle and fastening seat belts while driving, can prevent such accidents.

Findings support that most accidents have occurred mostly in months of September (11.8\%), July (10.63\%), and August (10.33\%), on Thursdays (15.4\%), and during the hours 12 to $15(20.09 \%)$ and 18 to $21(19.73 \%)$. In Hajinabi and colleagues study [15], most accidents have occurred in October and between the hours 18 to 19, and in the epidemiological examination study by Kasmaei and colleagues [17] of traffic accidents reported by Gilan Province Aid and Relief Administration, most accidents happened during the summer $(33 \%)$. Our present study findings and other studies such as the one conducted in the United States [22] indicate that most accidents have occurred during holidays and these accidents can be interpreted by considering the previous findings regarding the victims' age group. This age group [15-25] 
comprised mostly of high school and university students who during summer and days such as Thursday (results obtained from the study) have more leisure time and thus mostly engaged in driving.

The obtained time indicators have shown that the time intervals between receiving the call for help till announcing the mission was 20 seconds on average, and $50 \%$ of announcement took between 0 and 15 seconds; the time interval between announcing the mission till the ambulance leaving the operation base was 1 minute and $53 \mathrm{sec}-$ onds on average and $73 \%$ of them took in the time span of 1 to 3 minutes; the time interval between receiving the message and leaving the operation base was 2 minutes and 13 seconds on average and $47 \%$ of missions were completed between 2 to 4 minutes; the time interval between leaving the operation base till reaching the scene of accident is 6 minutes and 15 seconds on average, and in $40 \%$ of missions it took between 3 to 6 minutes; the time interval between receiving the message till reaching the scene of accident was 8 minutes and 42 seconds on average and $46 \%$ of missions were completed in the time span 4 to 8 minutes; and $50 \%$ of missions were carried out in less than 8 minutes; the time interval between departing the scene of accident till reaching the hospital was 11 minutes and 55 seconds on average and in $50 \%$ of missions the time span was less than 10 minutes; the time interval between receiving the message till reaching the hospital was 31 minutes on average and in $45 \%$ of missions the time span was less than 30 minutes; the time interval between receiving the call for help till completing the mission was 38 minutes on average and in $65 \%$ of missions the time span was less than 45 minutes; and finally the time interval between receiving the call for help till the ambulance returns to base was 2 hours on average and in $21 \%$ of missions the time span was 60 to 90 minutes.

The most important time interval is the response time. According to standards and regulations on pre-hospital emergency services comprehensive coverage, $80 \%$ of urban missions of emergency services should be accomplished within a time span of less than 8 minutes (here, the time interval is the same response time which is equal to the time from receiving the message or call for help till the ambulance reaches the scene of the accident). In this study, approximately half of the missions had been performed in less than 8 minutes and average value of this interval did not have difference with the standard time prescribed by regulations.

Based on Moradian and colleagues study [23], approximately $50 \%$ of the missions have been performed within the time interval of 8 to 20 minutes and beyond the prescribed standard time. In Rahbar Tarmasi study [24], the average response time was 6 minutes and 45 seconds and the time interval for transferring the victims from the scene of accident till reaching the hospital was reported as 9 minutes and 24 seconds. In Sladjana and colleagues study [18], the average time between receiving the call till announcing to the operation base was 1 minute and 32 seconds and time taken from receiving the message till reaching the scene of accident was reported as 7 minutes and 5 seconds.

Also, according to Wiser et al. study [19] in rural areas, the average response time was 12 minutes and 8 seconds, the average time of the dispatch unit was 52 seconds, the average time from receiving the message till reaching the scene of accident was 2 minutes and 15 seconds, and the average time from leaving the base till reaching the scene of accident was obtained as 6 minutes. This study (as compared with other studies) analyzed all time durations in emergency missions separately and because of this, there are no similar studies for all mentioned time intervals. For emergency victims of accidents, time is of one of the most important factors in their treatment and the sooner for medical emergency services to reach the side of patients, the better will be the effectiveness of medical emergency missions.

Findings of this study showed that instructions by consultant physician at the message center and communications with paramedics at the scene of the accidents in $70 \%$ of missions, were treatment and dispatch to hospital. Also the result of $70 \%$ of missions of Emergency 115 was to transfer the victims to hospital, and $7.5 \%$ of victims were transferred to hospital by private vehicles. Based on the evidence, as the physician is uncertain about the patient's injuries at the scene of accident, he or she could not prescribe any particular measure for the victim and would instruct the EMS crew to stabilize patients and dispatch them to the hospital. Considering the instructions given by the physician, it is logical that the result of $70 \%$ of missions is to transfer the victims to hospital.

Certainly, it cannot be said that all of these people transferred to hospital needed hospital treatment procedures and this issue requires separate investigation. In Hamidreza Aghababaeian et al. study [25], it was found that $83 \%$ of missions, in Rahbar Tarmasi and colleagues study [24], 53\% of missions, and in Hajinabi and colleagues study [15], 56\% of missions resulted in the transfer of patients to hospitals and $18 \%$ of victims had left the scene of accident by private vehicle before the ambulance arrived. According to our study and other similar studies it is evident that a high number of mis- 
sions ends in transfer of the victims to hospitals. This issue would require that the equipment needed for victims be available in ambulances and MICU (Medical Intensive Care Unit) ambulances be available for critical cases. Also, because the victims should be taken to hospital in the shortest time possible, steps should be taken to resolve the infra structural and operational issues that cause delay in this time interval (from the scene of accident till reaching the hospital) so that the victims can receive prompt and quality services in proper time.

The findings obtained regarding traffic accidents in terms of the vehicles have made it clear that most injured people by accidents were in a collision between car and motorcycle, and then between car and pedestrian. About $31 \%$ of the injured (8741 persons) were the result of collision between car and motorcycle and $17 \%$ (4593 persons) of accidents were the result of collision between car and pedestrian. The abundance of motorcyclist in the streets, their disregard toward traffic rules and regulations, and careless use of safety helmet can be accounted as causes for the high number of victims among motorcycle riders. In Alireza Ghorbanibirgani et al. study [20], 57\% of fatalities were the result of car collisions and $17 \%$ were the result of motorcycle collisions (epidemiologic study in the Province of Khuzestan). Also, in Vahid Monsef Kasmaei et al. study [17], most traffic victims were motorcyclists (49.9\%) and car passengers (33.8\%). Considering the high number of motorcycle rider victims, executing the rules and regulations and promoting public awareness regarding how to use this vehicle can be effective in reducing the number of victims.

The study's findings regarding the condition of Emergency 115 ambulances have shown that at present 52 ambulances are active. Of them, 36 active ambulances with average operation of $116204 \mathrm{~km}$ of distance covered and 16 auxiliary ambulances with average operation of $84016 \mathrm{~km}$ of distance covered are being utilized. Twenty-one of them are 2009 models and their average operation has been obtained as $86610 \mathrm{~km}$. Several factors have been implicated in wearing out an ambulance, such as duration of operation of the ambulance per year or in kilometers it has traversed.

Unfortunately, there is no standard for this issue and after discussing that with responsible officials of the vehicles unit, they mentioned that the ambulances with working age of 5 years and more are practically worn out, however, due to shortages of ambulances in the Emergency 115 center, many available ambulances aged more than 5 years. The standard required number for ambulances is determined based on the population they cover in each region. Considering the population and the fact that urban medical emergency bases need at least two ambulances for each base, Mashhad needs 96 ambulances and therefore, the difference between the status quo and the standard number is 44 ambulances.

Services provided by Emergency 115 crew can be categorized in two groups. The first group includes services that should be performed for all victims and are primary and necessary measures such as monitoring vital signs, examining the victim and obtaining his or her medical history. These services are not dependent on any factors and performing them is necessary for all victims. Considering the obtained findings, it was found that in $53 \%$ of the files, CVS (Concussion Vital Signs) and vital signs (blood pressure, body temperature, pain, respiratory rate, pulse rate) have been checked for all patients as it should be.

The second group includes measures that are performed based on the circumstances of the injury inflicted on the victim and performing them is not necessarily required for all victims. These measures are performed based on the knowledge of the paramedics and with consultation (depending on the injury) received from the resident physician at the emergency call center. Also, the findings obtained regarding the steps taken for the victims showed that $96.92 \%$ of the victims have been transferred to the hospital and this transfer service has been performed for most victims. For $96.72 \%$ of victims, the injections needed have been carried out, $98 \%$ of the injections were of the IV (Intravenous) route. Stabilizing body limbs have been performed for $59.35 \%$ of victims, of which $43 \%$ needed splinting, 32\% needed fixing the spine, and for $23 \%$ cervical collar was used.

In Tarmasi and colleagues study [24], it was found that $30 \%$ of victims received IV injections and $10 \%$ were stabilized. Also, in Ali Bidari and colleagues study in 2006, 92.3\% of victims had their blood pressure measured, $88 \%$ had their heart rate measured, $83 \%$ their respiratory rate, and for $71 \%$ their body temperature was measured. Also, 74\% had IV injections, 5\% cervical collar and 7\% bleeding control. Considering the type of pre-hospital emergency system in Iran, this stage is one of the stages that appropriate interaction and communications should be established between the emergency center resident physician and the EMS crew sent to the scene of accident so that services needed for the victims can be provided for them. If this interaction and confidence does not exist between these two treatment groups, then, the physician cannot make correct decision regarding the conditions and situation of the 
patient and would instruct the group at the scene of accident to transfer the patient to the hospital.

Due to the special circumstances in the city of Mashhad, generalizing the results of this study to other cities of Iran should be done with more caution. Considering that collection of data was in the secondary form and through the files of traffic accidents victims, the research team was confronted with incompleteness of files due to lack of record of the physician's instructions and the measures taken by crew of medical emergency in various sections, and these were among limitations of this research.

\section{Conclusion}

The highest risk group in traffic accidents are young people, especially men. Instructions directed toward this group, especially the young people should be brought into attention. There have been large number of instructions on treatment and dispatch given by the consultant physician at the emergency call center and communications to EMS crew at the scene of accidents, and consequently these missions resulted in the transfer the victims to the hospitals. Considering that a high number of missions end in the transfer the victims to hospitals, the necessary equipment for the victims should be available in ambulances, and MICU ambulances should be available for critical cases.

Certainly, all the persons transferred to hospital may not need the transfer, however, because the consultant physician is uncertain of the patient's status, and in some occasions, the insistence by patients for transfer, the number of these transfers rises. One of the reasons for this, is the EMS (Emergency Medical Service) system in Iran in which the physician is not present at the side of the patient at the scene of accident. Also, steps need to be taken with regard to modernizing the Emergency 115 ambulances in order to improve the quality of services and satisfy the patients. Services provided to the victims of traffic accidents should be with regard to the injuries inflicted on them.

This study made it clear that after transferring the victim to hospital, the body limbs stabilization service was one of the services that was performed for half of the victims indicating that equipment for body limbs stabilization are among the necessities that should be considered and the emergency call services should examine their equipment in terms of being sound, in proper condition, and in sufficient number.
Mashhad Emergency 115 center in order to reach standard conditions and to provide better servicers should improve its manpower in this respect (resolving the shortage in the medical and non-medical work force, rank, file, and staff), equipment (addressing shortages in equipment for aid, treatment, radio, ambulance and motorlance (motorcycle ambulance) of emergency base centers as well as Emergency 115 command and communications center of the city of Mashhad, construction (building ten earthquake resistant medical emergency bases and also command and communications center), also in management and the software required, all of which should be included in future plans of the said organization.

\section{Acknowledgments}

The present article is the result of Payam Mahmoudian's MSc. thesis registered under code number 922674 at the office of the Vice President for Research of Mashhad University of Medical Sciences. The researcher hereby acknowledges and expresses thanks and gratitude toward colleagues at pre-hospital medical emergency of the city of Mashhad who cooperated in data collection and analysis, especially Mrs. Akbari and Mr. Alishahi.

\section{Conflict of Interest}

The authors declared no conflicts of interest.

\section{References}

[1] World Health Assembly. Health systems: Emergency-care systems. Geneva: World Health Organization; 2007.

[2] Bahrami MA, Ranjbar-Ezzatabadi M, Maleki A, Asqari R, Ahmadi-Tehrani G. [A survey on the Yazd pre-hospital emergency medical services' performance assessment, 2009-2010 (Persian)]. Toloo-e Behdasht. 2011; 9(4):45-59.

[3] Vafaee-Najar A, Esmaeili H, Ibrahimipour H, Dehnavieh R, Nozadi MS. [Motorcycle fatal accidents in Khorasan Razavi province, Iran (Persian). Iranian Journal of Public Health. 2010; 39(2):95.

[4] Vafaee-Najar A, Khabbazkhoob M, Alidadi-Soltangholi H, Asgari S, Ibrahimipour $\mathrm{H}$. [Investigating the relative risk factors of injuries caused by accidents on roads in the Mashhad area in 2007 (Persian)]. Iranian Red Crescent Medical Journal. 2011; 13(8):530.

[5] Roudsari BS, Shadman M, Ghodsi M. Childhood trauma fatality and resource allocation in injury control programs in a developing country. BMC Public Health. 2006; 6:117. doi: 10.1186/1471-2458-6-117 
[6] Panahi F, Mohebbi HA, Farahani MA, Vishteh HR, Assari S. [Prehospital emergency service for internal medicine problems in pediatrics: Causes, time indices and outcomes (Persian)]. Iranian Journal of Pediatrics. 2007; 17(2):179-85.

[7] Nasiripur AA, Bahadori MK, Tofighi S, Gohari MR. [Prehospital emergency performance in Iran: View of comprehensive coverage plan (Persian)]. Journal of Critical Care Nursing. 2010; 2(4):3-4.

[8] Emergency Medical Services Review Committee. Saskatchewan emergency medical services review: Final report. Saskatchewan: Saskatchewan Health; 2009.

[9] Esmaeili Vardanjani A, Moghadasi J, Rafiei H, Masoudi R, Mohammadi M, Lalegani H, et al. [Satisfaction from pre-hospital emergency medical services: A cross sectional study in Shahrekord (Persian)]. Journal of Clinical Research in Paramedical Sciences. 2014; 3(2):103-13.

[10] Sadeghi Hasan Abadi A, Delkhosh M, Mehdizadeh S. [Prehospital emergency care for traumatic patients and events (Persian)]. Paper presented at: The $2^{\text {nd }}$ Conference of National Emergency Medicine; 29 May 2007; Tehran, Iran.

[11] Haghparast-Bidgoli H, Hasselberg M, Khankeh H, Khorasani-Zavareh D, Johansson E. Barriers and facilitators to provide effective pre-hospital trauma care for road traffic injury victims in Iran: A grounded theory approach. BMC Emergency Medicine. 2010; 10:20. doi: 10.1186/1471-227x-1020

[12] Mohseni M, Khaleghdoost Mohammadi T, Adib M, Mohtasham Amiri Z, Yosefzadeh Sh, Kuchakinejad L, et al. [Situation of pre-hospital emergency neurological care and related factors in traumatic patients (Persian)]. Journal of Health and Care. 2014; 16(1):55-65.

[13] Bidari A, Abbasi S, Farsi D, Saeidi H, Mofidi M, Radmehr $M$, et al. [Quality assessment of prehospital care service in patients transported to hazrat-e- rasoul akram hospital (Persian)]. Medical Journal of Tabriz University of Medical Sciences. 2007; 29(3):43-6.

[14] Bahadori M. [Prioritization of determinants influencing preparedness of Iranian pre-hospital emergency services (Persian)]. Journal of Critical Care Nursing. 2011; 4(2):73-8.

[15] Haj-nabi K, Riyahi L, Gholipur-varaki H. [The relationship between pre-hospital time indices and on-scene death rate in traffic accidents in the 22 regions of Tehran (Persian)]. Health Information Management. 2014; 11(3):353-61.

[16] Najjari F, Asghar-zade B, Sadri A. [A study of pre-hospital causes of road accidents in patients Admitted at emergency ward of Shohadaye -7tir hospital between Aug 2008 to Sep 2009 (Persian)]. Journal of Medical Council of Iran. 2012; 29(3):230-6.

[17] Monsef Kasmayi V, Assadi P, Maleki Ziabari SM. [The epidemiologic of the traffic accidents helped by EMS, Gilan 2011-2013 (Persian)]. Scientific Journal of Forensic Medicine. 2014; 20(2):55-60.

[18] Ferrando J, Plasència A, Ricart I, Canaleta X, Seguí-Gómez $M$. Motor-vehicle injury patterns in emergency-department patients in a South-European urban setting. Annual Proceedings/Association for the Advancement of Automotive Medicine. 2000; 44:445-58. PMCID: PMC3217388
[19] Tiwari R, Ganveer G. Injury pattern among non-fatal road traffic accident cases: A cross-sectional study in Central India. Indian Journal of Medical Sciences. 2005; 59(1):9. doi: 10.4103/0019-5359.13812

[20] Ghorbani A, Hakim A, Zare K. [Epidemiology of fatal traffic accidents in Khuzestan province in 1389 (Persian)]. Scientific Journal of Rescue \& Relief. 2012; 4(2):28-35.

[21] Sadeghian F, Khosravi AH, Emamian MH, Younesian R. [The pattern of road traffic injuries and related factors in Shahrood, Iran (Persian)]. Payesh Health Monitor. 2008; 7(3):225-33.

[22] Kong LB, Lekawa M, Navarro RA, McGrath J, Cohen M, Margulies DR, et al. Pedestrian-motor vehicle trauma: An analysis of injury profiles by age. Journal of the American College of Surgeons. 1996; 182(1):17-23. PMID: 8542084

[23] Peyravi MR, Moradian MJ, Ettehadi R, Pourmohammadi $\mathrm{K}$. [Studying the time of response and results of delay in emergency medical system in Shiraz (Persian)]. Scientific Journal of Rescue \& Relief. 2013; 5(2):30-9.

[24] Bury G. Pre-hospital emergency care in Ireland. Emergency Medicine Journal. 2005; 22(12):893. doi: 10.1136/ emj.2005.031591

[25] Vahidi A, Arzemani M, Jafakesh-Moghadam A, Vahidi M, Hashemi M. [Investigating performance of emergency units of hospitals which belonged to North Khorasan University of Medical Sciences in 2012 (Persian)]. Journal of North Khorasan University of Medical Sciences. 2013; 5(1):159-65. 
